\title{
Pollution of potentially toxic metals in urban road dust in Dushanbe (Tajikistan)
}

\author{
Khasan Nazriddinzoda ${ }^{1}$, Valery Udachin ${ }^{2}$, Ivan Blinov ${ }^{2}$, Mikhail Shtenberg ${ }^{2}$, Pavel Aminov $^{2}$ *, and Nikolay Udachin ${ }^{2}$ \\ ${ }^{1}$ South Ural State University, 454080 Chelyabinsk, Lenin street 76, Russia \\ ${ }^{2}$ Institute of Mineralogy, Ural branch Academy Science of Russia, 456317 Miass, Russia
}

\begin{abstract}
Heavy metal contamination in the road dust due to traffic in the capital city of Tajikistan was investigated. Concentrations of potentially toxic elements ( $\mathrm{Ba}, \mathrm{Cu}, \mathrm{Cd}, \mathrm{Co}, \mathrm{Cr}, \mathrm{Pb}, \mathrm{Ni}, \mathrm{Zn}$ and $\mathrm{As}$ ) in particle size of $63 \mu \mathrm{m}$ were analyzed. The highest potentially toxic element concentration was $\mathrm{Zn}$ $(312 \mathrm{mg} / \mathrm{kg})$, whereas the lowest was Co $(5.3 \mathrm{mg} / \mathrm{kg})$. The biggest contribution to road dust is atmospheric deposition due to metal traffic density makes slight contribution to heavy metal contamination. According to the calculation on enrichment factor (EF), heavy metals decrease in the order of $\mathrm{Sb}>\mathrm{Cd}>\mathrm{As}>\mathrm{Cu}>\mathrm{Zn}>\mathrm{Pb}$. The Dushanbe city road dust particles are potentially influenced by minimum three sources of metals including: urban sources (vehicles traffic, etc.); industrial sources (cement, reinforcement plant, etc.); geogenic sources (soils, dusts, rock weathering, etc.).
\end{abstract}

Road dust, an accumulation of solid particles on outdoor ground surfaces, is a valuable medium for characterizing urban environmental quality. Road dust in urban area is an indicator of heavy metal contamination from atmospheric deposition. It may act as a temporary sink of metals from a variety of sources and may also act as a source of metals contributing to atmospheric pollution through resuspension. Road dust particles with less than $100 \mu \mathrm{m}$ in diameter are vital component in atmospheric particulate matters due to its suspendability characteristics by atmospheric, vehicle exhaust emissions, and nonexhaust emissions factors. During suspendability process, composition of road dust undergoes geochemical changes and finally accumulates as pollutants carrier in urban area.

Dushanbe, the capital city of Tajikistan is located in western part country with a population of over 0.82 million. A total of 15 road dust samples were collected from trunk roads in the highly urbanized region of Dushanbe in July, 2018. Road dust materials were collected by gently sweeping an area of about $0.5 \mathrm{~m}^{2}$ adjacent to the curb of the road with a plastic hand broom and transferring the dust to a polyethylene bag. In the laboratory, samples were oven-dried at $60{ }^{\circ} \mathrm{C}$, mechanically passed through a $2 \mathrm{~mm}$ nylon sieve to remove large debris and then sieved though a $63 \mu \mathrm{m}$. Weighted samples $(0.4 \mathrm{~g})$ were sequentially digested with $\mathrm{HCl}-\mathrm{HNO}_{3}-\mathrm{HF}$ in a Teflon beaker. The acids used in the digestion were purified with a Berghof BSB-939IR sub-boiling apparatus. Concentrations of metals (Ba, $\mathrm{Cr}, \mathrm{Cu}, \mathrm{As}, \mathrm{Ni}, \mathrm{Co}, \mathrm{Cd}, \mathrm{Sb}, \mathrm{Pb}$, and $\mathrm{Zn}$ ) were determined using Inductively Coupled Plasma-Optical Emission Spectrometry (ICP-OES, Varian 720 ES, Ausralia) (Tab. 1). Data qualities were ensured through the use of a standard reference material SGD-2 (Gabbro, Russia). The particle morphology and element composition was detected with a scanning electron microscope (VEGA 3 UB, TESCAN, Czech Republic) equipped with an energy dispersive X-ray spectrometer (EDX)(SEMEDX) (INCA X-act, Oxford, UK). The instrumental parameters used were, accelerating voltage $15 \mathrm{kV}$, beam current of $3 \mathrm{nA}$, working distance $24 \mathrm{~mm}$ and acquisition time of $100 \mathrm{~s}$.

Enrichment factor (EF) is often used for the evaluation of the pollution level of environmental samples. The EF was determined using the following equation:

$\mathrm{EF}_{\text {metal }}=([\text { metal }] /[\mathrm{Sc}])_{\text {sample }} /([\text { metal }] /[\mathrm{Sc}])_{\text {continental crust }}$

where "metal" refers to the metals, using continental crust values reported in Taylor and Mc Lennan [1]. Scandium is used as the reference element for normalization. The usual practice of rationing when calculating EF is to use as an element of comparison either an element with stable high $(\mathrm{Fe}, \mathrm{Al})$ or with stable low (Ti, Sc, Y) content in the earth's crust. Using Sc for EF calculations has proven itself in assessing pollution from technogenic atmospheric aerosol [2-4] and also for surface urban soils and street dust [5].

According to the calculation on enrichment factor (EF), heavy metals decrease in the order of $\mathrm{Sb}>\mathrm{Cd}>\mathrm{As}>\mathrm{Cu}>\mathrm{Zn}>\mathrm{Pb}$ (Fig. 1). The EF for $\mathrm{Sr}, \mathrm{Ba}, \mathrm{Cr}$, $\mathrm{Ni}$ does not show anomalous values.

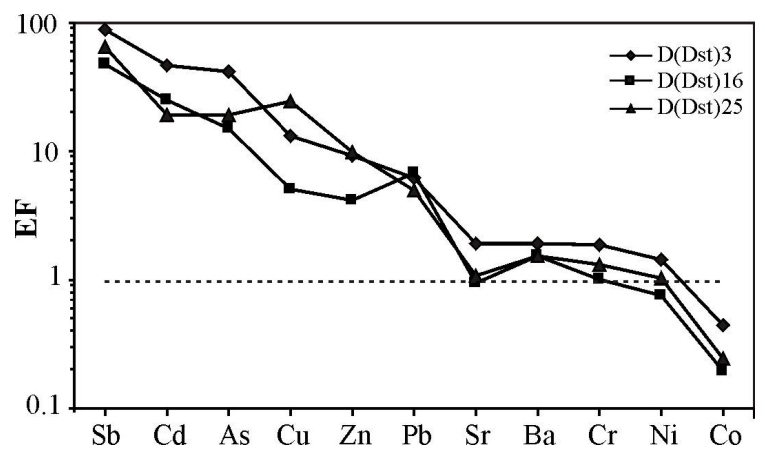

Fig. 1. Enrichment factors of metals and metalloid in road dust Dushanbe. 
Table 1. Chemical composition of road dust samples Dushanbe ( $\mathrm{mg} / \mathrm{kg})$

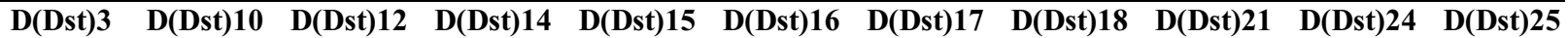

\begin{tabular}{|c|c|c|c|c|c|c|c|c|c|c|c|}
\hline As & 10.7 & 15.5 & 13.7 & 11.0 & 13.0 & 10.7 & 12.8 & 13.8 & 13.3 & 15.9 & 12.3 \\
\hline $\mathbf{B a}$ & 178 & 499 & 421 & 401 & 399 & 405 & 429 & 436 & 425 & 402 & 366 \\
\hline Cd & 0.77 & 0.67 & 0.66 & 0.58 & 1.35 & 1.16 & 0.54 & 0.72 & 0.58 & 0.50 & 0.80 \\
\hline Co & 5.33 & 7.90 & 7.83 & 7.23 & 6.99 & 6.51 & 7.27 & 9.86 & 7.64 & 8.23 & 7.38 \\
\hline $\mathrm{Cr}$ & 27.0 & 49.4 & 67.7 & 44.0 & 40.9 & 40.8 & 47.5 & 62.5 & 62.1 & 51.7 & 48.3 \\
\hline $\mathrm{Cu}$ & 56.3 & 207 & 1307 & 85.9 & 99.7 & 60.5 & 135 & 950 & 106 & 207 & 261 \\
\hline $\mathbf{N i}$ & 10.7 & 23.6 & 24.1 & 16.5 & 17.5 & 15.7 & 17.8 & 26.5 & 24.2 & 19.8 & 19.5 \\
\hline $\mathbf{P b}$ & 18.0 & 75.1 & 54.6 & 39.6 & 33.6 & 54.8 & 58.3 & 58.0 & 83.8 & 46.2 & 36.5 \\
\hline Sb & 2.98 & 12.1 & 6.22 & 5.39 & 7.08 & 4.51 & 8.17 & 6.90 & 8.13 & 7.31 & 5.61 \\
\hline Sc & 2.31 & 7.45 & 6.43 & 6.72 & 7.11 & 6.45 & 6.60 & 7.07 & 6.36 & 7.21 & 5.82 \\
\hline Sr & 115 & 158 & 190 & 162 & 169 & 158 & 162 & 177 & 182 & 166 & 161 \\
\hline $\mathbf{Z n}$ & 111 & 248 & 298 & 269 & 289 & 141 & 199 & 312 & 291 & 176 & 301 \\
\hline
\end{tabular}
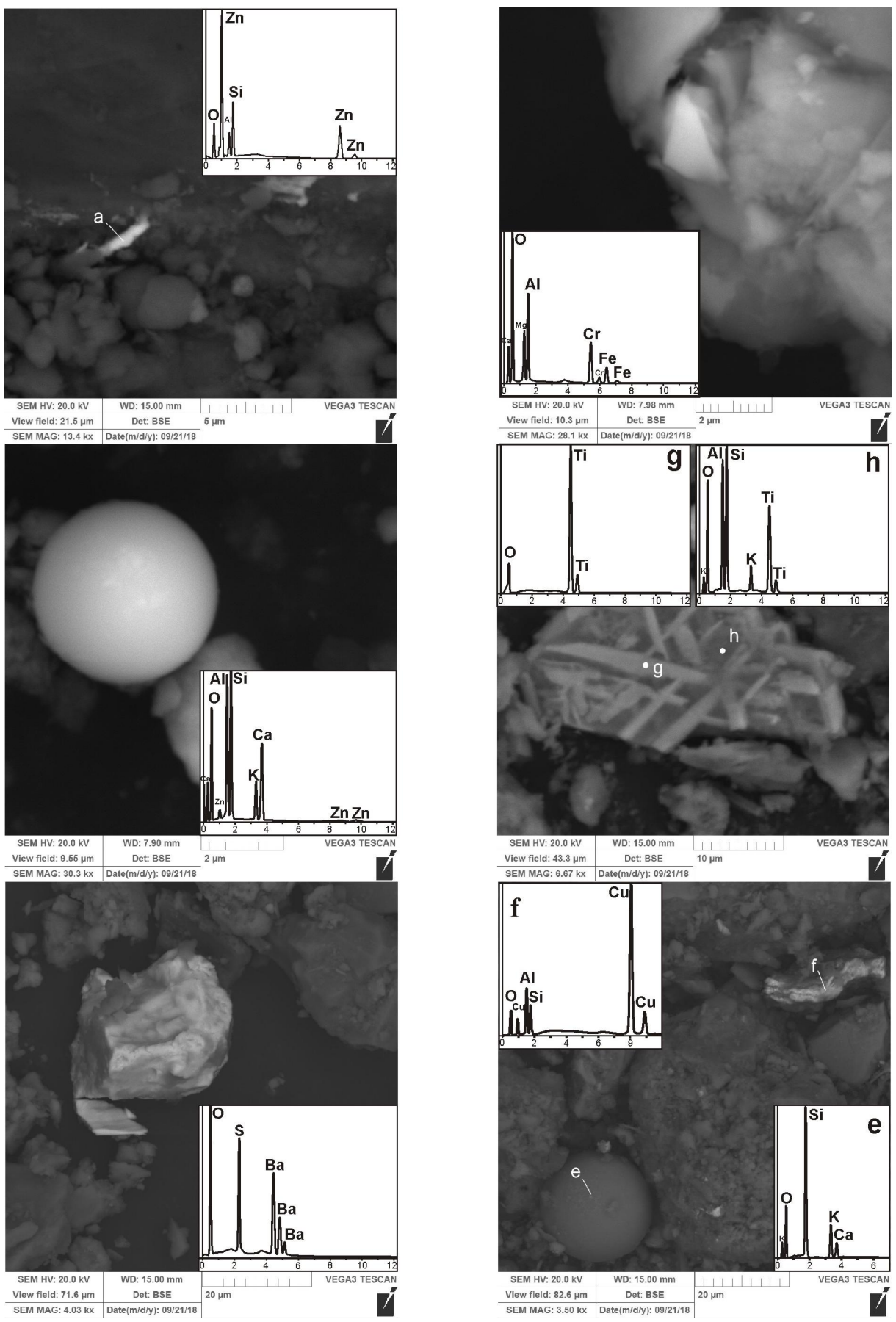

Fig. 2. Micrographs and EDX spectra of road dust particles Dushanbe. 
Five contamination categories are recognized on the basis of EF [6-9]: $(<2)$ - deficiency to minimal enrichment, (2-5) - moderate enrichment, (5-20) significant enrichment, (20-40) - very high enrichment, and $(>40)$ - extremely high enrichment. According to this classification, many road dust samples in Dushanbe are significant enriched by $\mathrm{Pb}, \mathrm{Zn}$, and $\mathrm{Cu}$. All samples is also extremely high enriched by $\mathrm{As}, \mathrm{Cd}$, and $\mathrm{Sb}$. It should be noted that a $\mathrm{Pb}$ are sourced from non-exhaust vehicle emissions. The significant enrichment is observed for $\mathrm{Cu}$ and $\mathrm{Zn}$ (the main non-exhaust trafficrelated pollutants). In urban areas Dushanbe, abrasion of tires mainly releases dust with $\mathrm{Zn}$. The brake systems of motor vehicles mainly discharge particles with $\mathrm{Cu}$ and $\mathrm{Sb}$ associated with them.

The SEM-EDX data show that road dust particles have a mixed origin. One part has a mineral origin (silicates, aluminosilicates, barite, zircon, etc.). The other part has anthropogenic origin and includes particles of fly ash, Ticontaining glass, $\mathrm{Zn}$-containing particles from galvanized car parts and $\mathrm{Cu}$-containing particles from the braking car system (Fig. 2). In accordance with previously published data for different urban position, it is possible to assume the influence of motor transport on the source of individual anomalous elements. Because $\mathrm{Pb}$ is used as an antiknock agent in the gasoline combustion [10], and also, $\mathrm{Cu}, \mathrm{Sb}$ and $\mathrm{Cd}$ have emitted from road traffic [11]. Brake dust is already recognized as a significant carrier of $\mathrm{Cu}$ (used in brakes to control heat transfer) and $\mathrm{Sb}$ in aerosol composition [12]. $\mathrm{Zn}$ may have been derived from lubricating oils, tires, mechanical abrasion of vehicles [13].

This research supported by the State Contract. The part of this work was performed according to the Program of Ural branch Russian academy of sciences (№18-5-5-43).

\section{References}

1. S.R. Taylor and S.M. McLennan, The Continental Crust: Its Composition and Evolution. Blackwell, Oxford (1985)

2. A. Sorooshian, J. Csavina, T. Shingler, S. Dey, F.J. Brechtel, A.E. Sáez, E.A. Betterton, Environ. Sci. Technol., 46 (2012)

3. R. Arimoto, B.J. Ray, N.F. Lewis, U. Tomza, R.A. Duce, Geophys. Res., 102 (1997)

4. L. Cao, W.Z. Tian, B.F. Ni, Y.M. Zhang, P.S. Wang, Atmos. Environ., 36 (2002)

5. S. Abbasi, B. Keshavarzi, F. Moore, M.R. Mahmoudi, Environ. Earth Sci., 77 (2018)

6. R.A. Sutherland, Environ. Geol., 39 (2000)

7. Y.M. Han, P.X. Du, J.J. Gao, E.S. Posmentier, Sci. Total. Environ., 355 (2006)
8. M.S. Ermolin, P.S. Fedotov, A.I. Ivaneev, V.K. Karandashev, N.N. Fedyunina, A.A. Burmistrov, Chemosphere, 210 (2018)

9. S. Kartal, Z. Aydin, S. Tokalioglu, J. Hazard Mater., 132 (2006)

10. E. Manno, D. Varrica, G. Dongarrà, Atmos. Environ., 30 (2006)

11. H. Bem, M. Gallorini, E. Rizzio, M. Krzemińska, Environ. Int., 4 (2003)

12. S. Huang, J. Tu, H. Liu, M. Hua, Q. Liao, J. Feng, Z. Weng, G. Huang, Atmos. Environ., 36 (2009)

13. H. Arslan, J. Trace Microprobe Tech., 3 (2001) 